\title{
Microscopic Characteristic and Chemical Composition Analysis of Three Medicinal Plants and Surface Frosts
}

\author{
Da Qing Yu ${ }^{1}$, Xiao Jing Han ${ }^{1}$, Ting Yu Shan ${ }^{1}$, Rui Xu ${ }^{1}$, Jin Hu ${ }^{1}$, Wang Xing Cheng ${ }^{1}$, \\ Liang Ping Zha ${ }^{1,2, *}$ and Hua Sheng Peng $1,3, *$ (D) \\ 1 College of Pharmacy, Anhui University of Chinese Medicine, Hefei 230012, China; \\ yudaqing0430@163.com (D.Q.Y.); jxhan511@163.com (X.J.H.); ShanTY3293055455@163.com (T.Y.S.); \\ ruixurui@126.com (R.X.); 18315339281@163.com (J.H.); wxcheng@ahtcm.edu.cn (W.X.C.) \\ 2 Institute of Conservation and Development of Traditional Chinese Medicine Resources, \\ Anhui Academy of Chinese Medicine, Hefei 230012, China \\ 3 Chinese Academy of Medical Sciences Research Unit (No. 2019RU057), National Resource Center for \\ Chinese Materia Medica, China Academy of Chinese Medical Sciences, Beijing 100700, China \\ * Correspondence: chaliangping520@126.com (L.P.Z.); hspeng@126.com (H.S.P.); \\ Tel.: +86-181-3002-8287 (L.P.Z.); +86-159-0569-2001 (H.S.P.)
}

Received: 31 October 2019; Accepted: 9 December 2019; Published: 12 December 2019

check for updates

\begin{abstract}
The accumulation of chemical constituents of some medicinal plants, such as Paeonia ostii T. Hong et J. X. Zhang, Houpoëa officinalis (Rehder and E. H. Wilson) N. H. Xia and C. Y. Wu. and Atractylodes lancea (Thunb.) DC, can precipitate on the surface and form frosts after natural or artificial intervention. The characteristics of these three medicinal plants and their frosts were analyzed by light microscope, polarizing microscope, stereomicroscope, and metalloscope. The results of ordinary Raman of $P$. ostii and H. officinalis showed that the frosts of $P$. ostii matched paeonol, while that of H. officinalis matched magnolol and honokiol. In P. ostii and its frost, 19 peaks were identified by UPLC-Q/TOF-MS, and the main component was paeonol. Eleven components were identified in H. officinalis and its frosts, and the main components were magnolol and honokiol. A. lancea and its frosts were analyzed by gas chromatography-mass spectrometry (GC-MS), 21 were identified, and its main components were hinesol and $\beta$-eudesmol. These three medicinal plants accumulate compounds and precipitate frosts on the surface. The results show that the components of the frosts provide a basis for quality evaluation and research on similar medicinal plants, and reveals the scientific connotation of "taking the medicinal materials' precipitated frosts as the best" of $P$. ostii, H. officinalis, and A. lancea, to some extent.
\end{abstract}

Keywords: Atractylodes lancea; chemical constituents; Houpoëa officinalis; Frosts; Paeonia ostii; UPLC-Q/TOF-MS; UPLC-Q Orbitrap; GC-MS

\section{Introduction}

During the metabolism of some plant cells, protoplasts produce substances that can accumulate in living cells, be released to the outside of cells, or be deposited in cavities or channels between cells. These substances are called as secretions [1]. The components of different plants show different accumulation patterns inside or outside the plants. For example, essential oil can be secreted by secretory cells in the leaves of Laurus nobilis L. [2]; mucilage accumulates in the seed coat, pericarp, or leaves [3,4]; white latex can flow out of the laticiferous canal in Decaisnea fargesii Franch. [5]; and digestive enzymes can be secreted in the Caryophyllales [6]. In addition to metabolites secreted by secretory cells in vivo, there are also some secretory cells which can secrete substances in vitro. 
For example, (-)-pulegone, (+)-menthone, and (+)-limonene are the major constituents of the glandular trichome in Schizonepeta tenuifolia Briquet [7], and artemisinin can be obtained from the secretory glandular hairs of Artemisia annua L. [8,9]. These play various roles in the growth and development of plants.

The secretion can be secreted in vitro or accumulated in vivo, mainly in the form of liquid. However, some plant secretions can precipitate on the surface. For example, salt-secreting plants, such as Aeluropus lagopoides L. [10], can secrete salt crystals from glands, and some Saxifraga species, such as alpine plant Saxifraga scardica [11,12], can discharge secretions through hydathodes to form calcite or hexagonal calcium sediment.

Some medicinal plants can produce translucent or white substances (these substances are referred to as "frost" in the following) on the surface of specific organs after being harvested and placed for a period of time. For example, persimmons can precipitate a layer of white frost on surface after storing for a period of time [13]. There are also drugs made according to this kind of white frosts, namely persimmon frost, which have the function of moistening lungs to stop coughing, promoting fluid, promoting the pharynx, and stopping bleeding [14]. Besides dried persimmon frost, there are some other medicinal plants with the same feature. For example, the "white frost" of Schisandra chinensis, the "bright silver stars" of P. ostii and H. officinalis, and the "frost" of A. lancea are thought to be superior. In the traditional identification in Chinese medicine, it is believed that the precipitated frost is closely related to quality evaluation of $P$. ostii, H. officinalis, and A. lancea, and have become one of the characteristics of quality evaluation [15-20].

P. ostii, H. officinalis, and A. lancea, as commonly used medicinal plants in clinics, have long medicinal histories (Figure 1) [21,22]. P. ostii has become one of the important woody oleaginous plants, with a high content of alpha-linolenic acid and the high oil content of the seeds, and its peony seed extract is a potential anticancer drug candidate [23-25]. In addition, the main active component in root bark of $P$. ostii is paeonol, which has anti-inflammatory, anti-tumor, anti-cardiovascular, and other pharmacological effects [26-28]. Magnolol and honokiol are the main active ingredients in H. officinalis, which have the effects of antifungal, anti-Saprolegnia, and analgesic activity [29-32]. A. lancea is a common medicinal plant, which has antitumor, anti-inflammatory, and other essential effects [33-35]. Atractylone, atractylodin, hinesol, and $\beta$-eudesmol are the main active components of $A$. lancea [36,37]. All these medicinal plants have the feature of forming frosts, and the presence or quantity of frosts is regarded as one of the criteria of quality. However, few studies have been reported on the frosts of these medicinal plants. Therefore, the main purpose of our experiment is to determine whether the frost formation and composition of these three medicinal plants are related to the quality of medicinal materials.
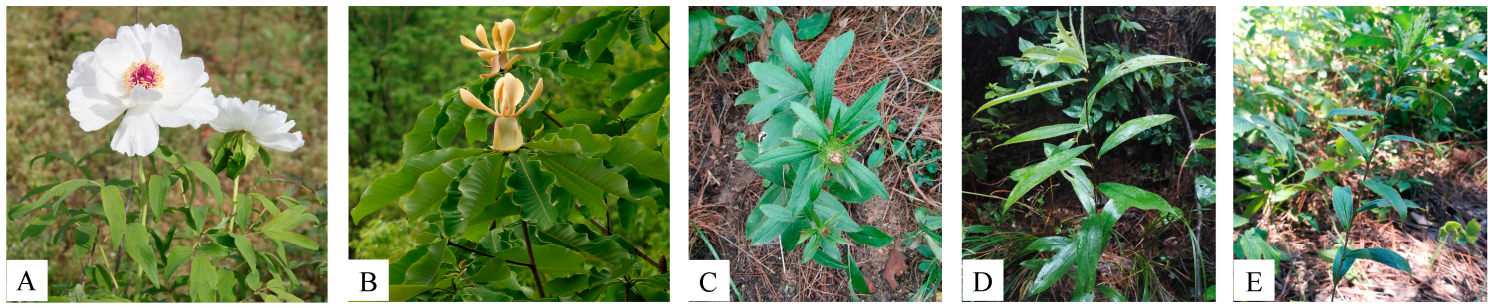

Figure 1. Three medicinal plants: (A) Paeonia ostii, (B) Houpoëa officinalis, (C) Atractylodes lancea from Tongbai Mountain, Henan: (D) A. lancea from Yuexi, Anhui, and (E) A. lancea from Nanjing, Jiangsu.

In this paper, three medicinal plants, P. ostii, H. officinalis, and A. lancea, and their frosts are analyzed. A polarizing microscope, stereomicroscope, and metalloscope were used to analyze the characteristics of frosts belonging to the three medicinal plants. Raman spectroscopy was used for the frosts of P. ostii and H. officinalis. Liquid chromatography coupled with mass spectrometry (LC-MS) and gas chromatography with mass spectrometry (GC-MS) have been widely used and become increasingly important [38-40]. In this study, we choose the most appropriate mass-spectrometric technique for 
the analysis of different samples, and UPLC-Q/TOF-MS, UPLC-Q Orbitrap, and GC-MS were used to analyze the P. ostii, H. officinalis, A. lancea, and their frosts, respectively.

\section{Results and Discussion}

\subsection{Characteristics of Three Medicinal Plants and Their Frosts}

\subsubsection{Characteristics of P. ostii and Its Frosts}

The root bark of $P$. ostii is tubular shaped with longitudinal fissures. The surfaces were greyish-brown or yellowish-brown, with numerous transverse lenticel-like prominences and rootlet scars, as well as an exfoliation site where the cork had fallen off, which was pink. The inner surface was pale greyish-yellow, with long, fine longitudinal striations (Figure 2A1). Bright frosts usually presented on the outer surface and cross section, at $0.2-0.4 \mathrm{~mm}$, and showed different shapes under stereomicroscope analysis (Figure 2A2). The frosts also had transparent and massive shapes under the light microscope (Figure 2A3), with strong polarization (Figure 2A4) [17,41,42].

\subsubsection{Characteristics of $H$. officinalis and Its Frosts}

The root bark of $H$. officinalis was greyish-brown or dark purple-brown on the outer surface and rough. The inner surface was brown or dark purple-brown and smooth. The granular section was greyish-brown in the outer layer and the inner layer was purple-brown or brown (Figure 2B1). Numerous small bright stars could be seen on the surface and section, which were transparent sheets under the light microscope (Figure 2B2,B3), and appeared blue and yellow under the polarizing microscope (Figure 2B4) [17,41,42].

\subsubsection{Characteristics of $A$. lancea and Its Frosts}

Three A. lancea samples were collected from Tongbai Mountain, Henan Province (Figure 2C1); Yuexi, Anhui Province (Figure 2D1); and Nanjing, Jiangsu Province (Figure 2E1). They were slightly curved, irregularly beaded, or nodular and cylindrical. The external surfaces of the rhizomes were greyish-brown with wrinkles, transverse lines, and residual fibrous roots, with stem scars or remnant stems at the apex. Their texture was solid and the sections were yellow-white, scattered with many orange or brown-red oil chambers. The A. lancea rhizomes from Tongbai Mountain, Henan, and Yuexi, Anhui were stronger, with more developed fibrous roots and orange oil chambers (Figure 2C2,D2). The A. lancea rhizome from Nanjing, Jiangsu was more delicate, with sparser fibrous roots and fewer brown-red oil chambers (Figure 2E2) [17,41,42].

The frosts of A. lancea rhizomes from three regions could precipitate out at cross-sections after a period of time; they were white fine needles. The frosts from Tongbai Mountain, Henan, and Yuexi, Anhui were obvious (Figure 2C3,D3), while the last frost was the least obvious in its presentation (Figure 2E3). Many frosts were near the oil chambers, and metallographic analysis showed them to be flexible (Figure 2C4,D4,E4) [17,41,42]. 


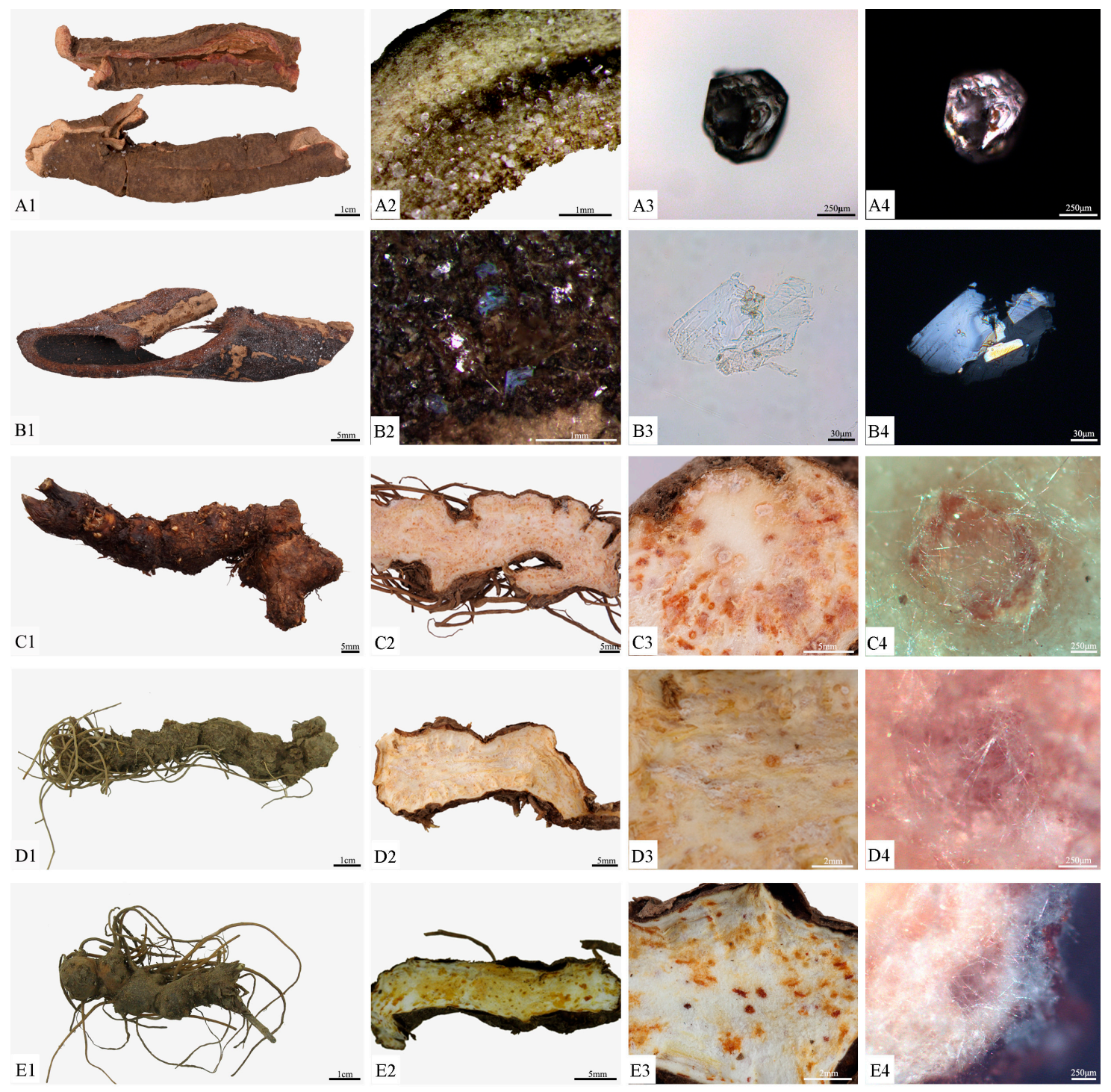

Figure 2. Medicinal materials and frosts of three medicinal plants: (A1) root bark of Paeonia ostii; (A2) frosts of $P$. ostii by microscope; (A3) frosts of $P$. ostii by light microscope; (A4) frosts of $P$. ostii by polarizing microscope; (B1) root bark of Houpoëa officinalis; (B2) frosts of H. officinalis by microscope; (B3) frosts of $H$. officinalis by light microscope; (B4) frosts of $H$. officinalis by polarizing microscope; (C): Atractylodes lancea rhizome from Tongbai Mountain, Henan; (D): A. lancea rhizome from Yuexi, Anhui; (E) A. lancea rhizome from Nanjing, Jiangsu; (C1, D1, E1) rhizomes of A. lancea; (C2, D2, E2) longitudinal section; (C3, D3, E3) detail of longitudinal section; (C4, D4, E4) the frosts.

\subsection{Chemical Analysis of P. ostii}

\subsubsection{Raman Results of P. ostii}

The Raman spectra of paeonol and the frosts in P. ostii were measured at $785 \mathrm{~nm}$ laser wavelength. As shown in Figure 3C, their Raman spectra are similar, as they are both in the range of $0-1700 \mathrm{~cm}^{-1}$; the vibration observed in the row wavenumber region of $200-500 \mathrm{~cm}^{-1}$ has been assigned to the $C-C$ bond. The vibration in the region of $518 / 518 \mathrm{~cm}^{-1}$ was attributed to $C-C$; the bands at $591 / 592 \mathrm{~cm}^{-1}$, $737 / 737 \mathrm{~cm}^{-1}$, and $1457 / 1457 \mathrm{~cm}^{-1}$ were related to stretching and deformation of the ring. The vibration at $711 / 711 \mathrm{~cm}^{-1}$ has been assigned to C-O-C stretching, and the vibration at $1072 / 1072 \mathrm{~cm}^{-1}$ has been assigned to $\mathrm{C}-\mathrm{O}-\mathrm{C}$. The deformation and ring vibrations at 1234/1234 $\mathrm{cm}^{-1}$ and $1256 / 1256 \mathrm{~cm}^{-1}$ were found to come from $\mathrm{C}-\mathrm{H}$; the strong bands at $1337 / 1338 \mathrm{~cm}^{-1}$ could be a result of the stretching 
vibration of $\mathrm{C}-\mathrm{O}$. The vibration at $1430 / 1429 \mathrm{~cm}^{-1}$ was the result of $\mathrm{O}-\mathrm{H}$ bending, and the peak at $1619 / 1619 \mathrm{~cm}^{-1}$ originated to the stretching of $\mathrm{C}=\mathrm{O}[43,44]$.
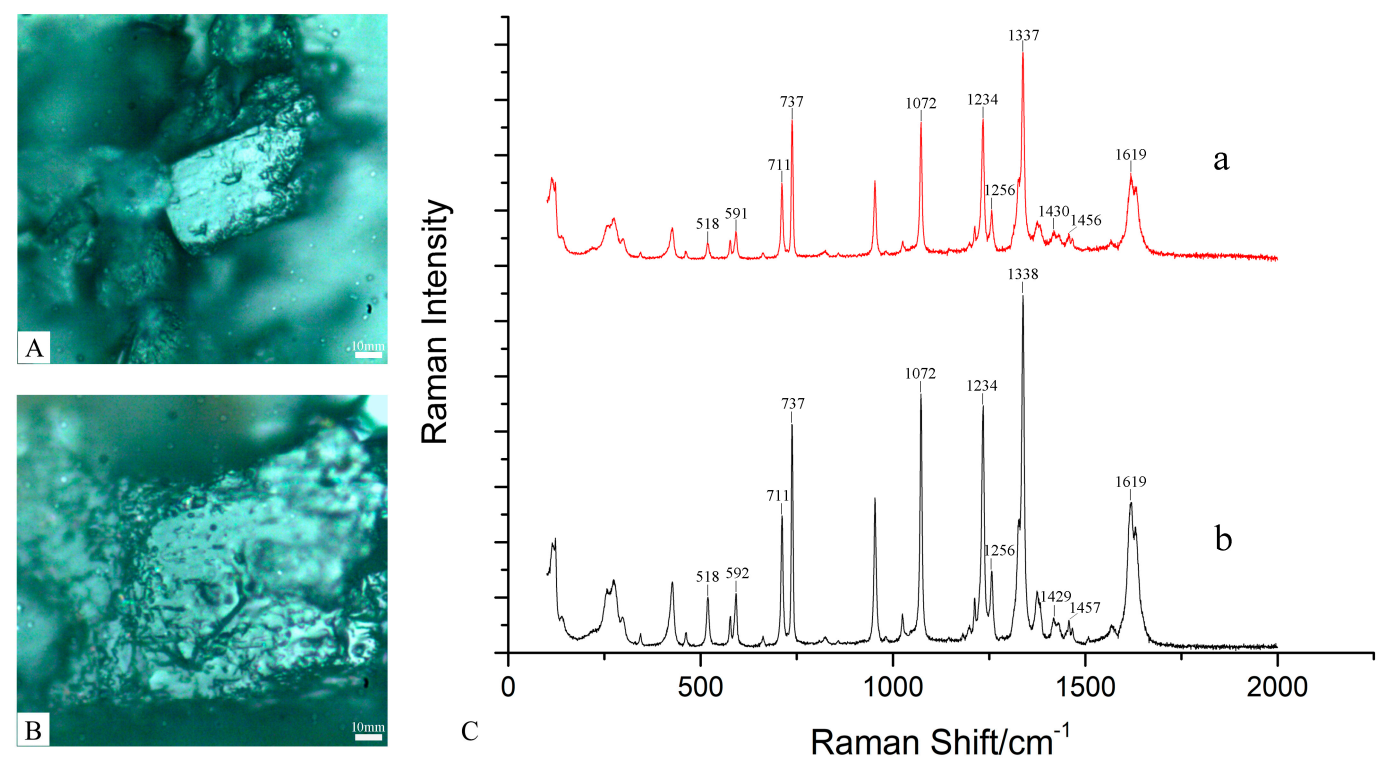

Figure 3. The micrograph and full Raman spectrum in paeonol and the frosts of Paeonia ostii: (A) micrograph of paeonol; (B) micrograph of frosts in P. ostii; (C) the full Raman spectrum of paeonol; (a) and frosts in P. ostii (b).

The results for paeonol and the frosts were similar. Therefore, the structure of the frosts of P. ostii is similar to paeonol, but the determination of the frost composition needs further exploration.

\subsubsection{Metabolite Profiling by UPLC-Q/TOF-MS}

The UPLC-Q/TOF-MS method was used to analyze the constituents of P. ostii and its frosts. In this study, total ion current (TIC) chromatograms of P. ostii and the frosts in P. ostii samples are shown in Figure 4A,B, respectively. In Figure 4A, 19 peaks have been identified, with two peaks identified in Figure 4B. Peak 19 was identified as paeonol by reference material, Peak 16 was not identified, and the peaks 16 and 19 are isomers. Paeonol was the main component of the frost precipitated from P. ostii. The other peaks were confirmed by the fragment ion, retention time and fragmentation pattern of the compounds reported in the literature. The data of the peaks are listed in Table 1 [45-49].

At present, $P$. ostii is a common medicinal plant, which is used as a root bark, rich in various active substances, such as paeonol [27]. The different organs of $P$. ostii have been determined. It has been found that the root bark of $P$. ostii is the most prominent component, followed by leaves, stems, and flowers, and the highest volume of paeonol was found in the cortex of root bark [50-52]. Therefore, the root bark is considered to be the accumulation of the active compounds in P. ostii. After the accumulation of these compounds in the root bark, paeonol precipitates in the form of frosts on the surface of the root bark.

\subsection{Chemical Analysis of H. officinalis}

\subsubsection{Raman Results of H. officinalis}

The Raman spectra of magnolol, honokiol, and the frosts of $H$. officinalis were measured at a $532 \mathrm{~nm}$ laser wavelength, which is shown in Figure 5. As shown in Figure 5D, the vibration in the region of 3013/3015/3013 $\mathrm{cm}^{-1}$ and 3056/3053/3056 $\mathrm{cm}^{-1}$ originated from C-H stretching of the phenyl. The band at $2907 / 2905 / 2907 \mathrm{~cm}^{-1}$ was related to stretching of the $\mathrm{C}-\mathrm{H}$, the band at $1613 / 1613 / 1613 \mathrm{~cm}^{-1}$ 
was a result of strong stretching of $C=C$, the band at $1341 / 1341 / 1342 \mathrm{~cm}^{-1}$ was attributed to the $C-O$ bending, and the vibration detected at 1317/1317/1317 $\mathrm{cm}^{-1}$ was the result of $\mathrm{C}-\mathrm{H}$ [44].

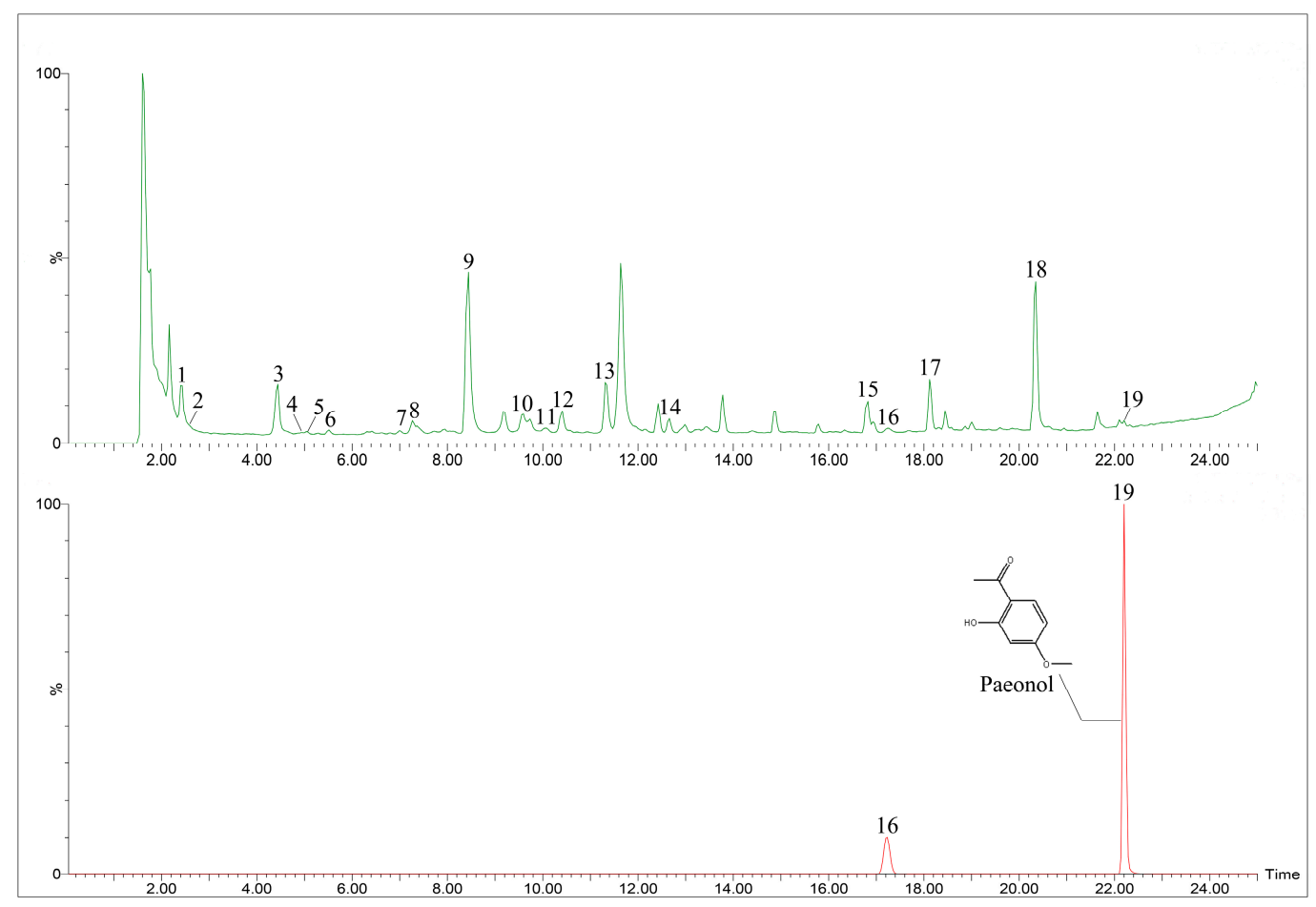

Figure 4. Liquid chromatography coupled with mass spectrometry (LC-MS) chromatograms of Paeonia ostii and its frosts: (A) P. ostii and (B) frosts of P. ostii.
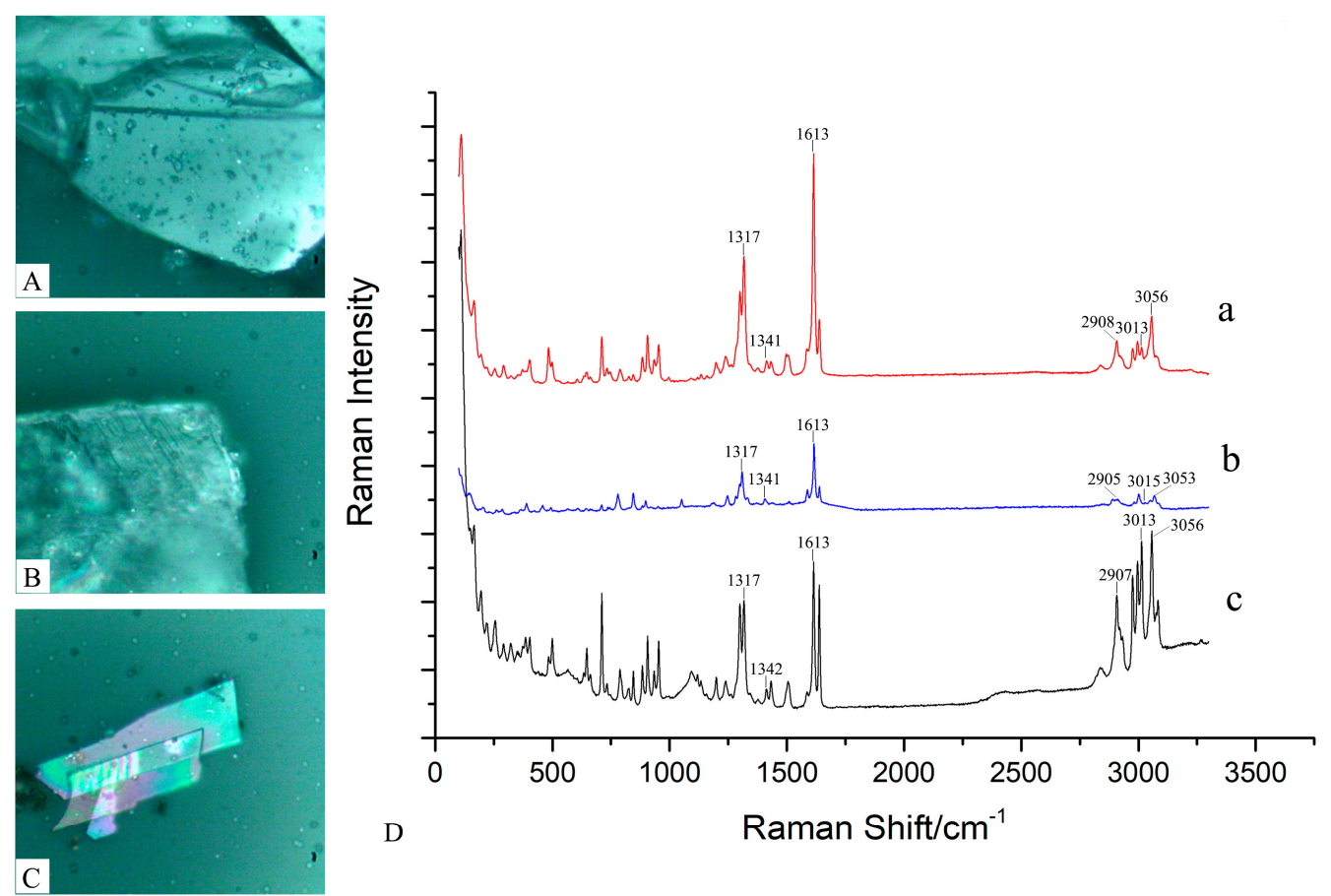

Figure 5. The micrographs and full Raman spectra for honokiol, magnolol, and frosts of Houpoëa officinalis: (A) micrograph of magnolol; (B) micrograph of honokiol; (C) micrograph of frost of H. officinalis; (D) full Raman spectrum of magnolol (a), honokiol (b), and frosts of H. officinalis (c). 
The results for magnolol, honokiol, and the frosts are similar, but the intensity of their respective peaks is slightly different. Therefore, it is speculated that the frost of $H$. officinalis may be a mixture of these two compounds or a single compound.

\subsubsection{Metabolite Profiling by UPLC-Q Orbitrap}

The UPLC-Q Orbitrap method was used to analyze the constituents of $H$. officinalis and the frosts of $H$. officinalis. In this study, TIC chromatograms of $H$. officinalis and the frosts of $H$. officinalis samples are shown in Figure 6A and 6B, respectively. Under the negative ion mode, 11 peaks are identified in Figure 6A and two peaks in Figure 6B. Peaks 9 and 11 were identified as magnolol and honokiol by reference material, which are the main chemical constituents of frost in $H$. officinalis. The other compounds were confirmed by the retention time, debris information, and fragmentation pattern of the peaks, which had previously been reported in the literature. The data for the peaks are listed in Table 2 [53-55].

H. officinalis is a commonly used medicinal plant, and the main active compounds are magnolol and honokiol. Zhao described the constituents of the frosts of H. officinalis as magnolol and honokiol [42]. The result of this study corroborated this result.

\subsection{Chemical Profiling of A. lancea and Its Frosts}

The medicinal materials of $A$. lancea and its frosts were analyzed by GC-MS. The TIC chromatograms of $A$. lancea rhizomes and their frosts were shown in Figure 7. A total of 21 peaks were identified, and according to reference material, peaks $1,19,20$, and 21 were identified as $\alpha$-pinene, $\beta$-eudesmol, atractylone, and atractylodin, respectively. Other peaks were confirmed by comparing the reported mass ions and retention time. The data of the peaks are listed in Table 3 [56-58].
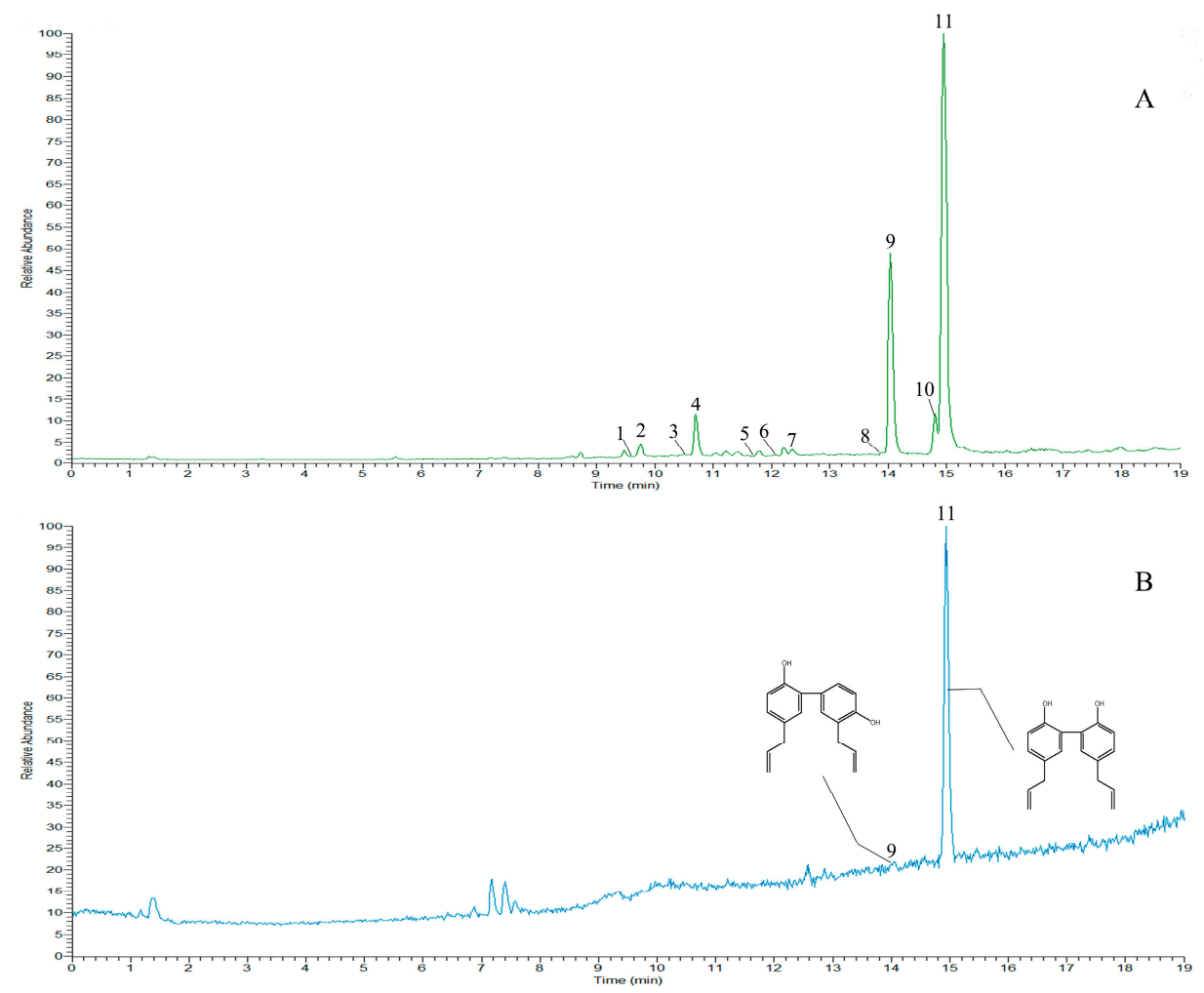

Figure 6. UPLC-Q Orbitrap chromatograms of Houpoëa officinalis and its frosts: (A) total ion current (TIC) chromatograms for H. officinalis; (B) TIC chromatograms for frosts of $H$. officinalis. 

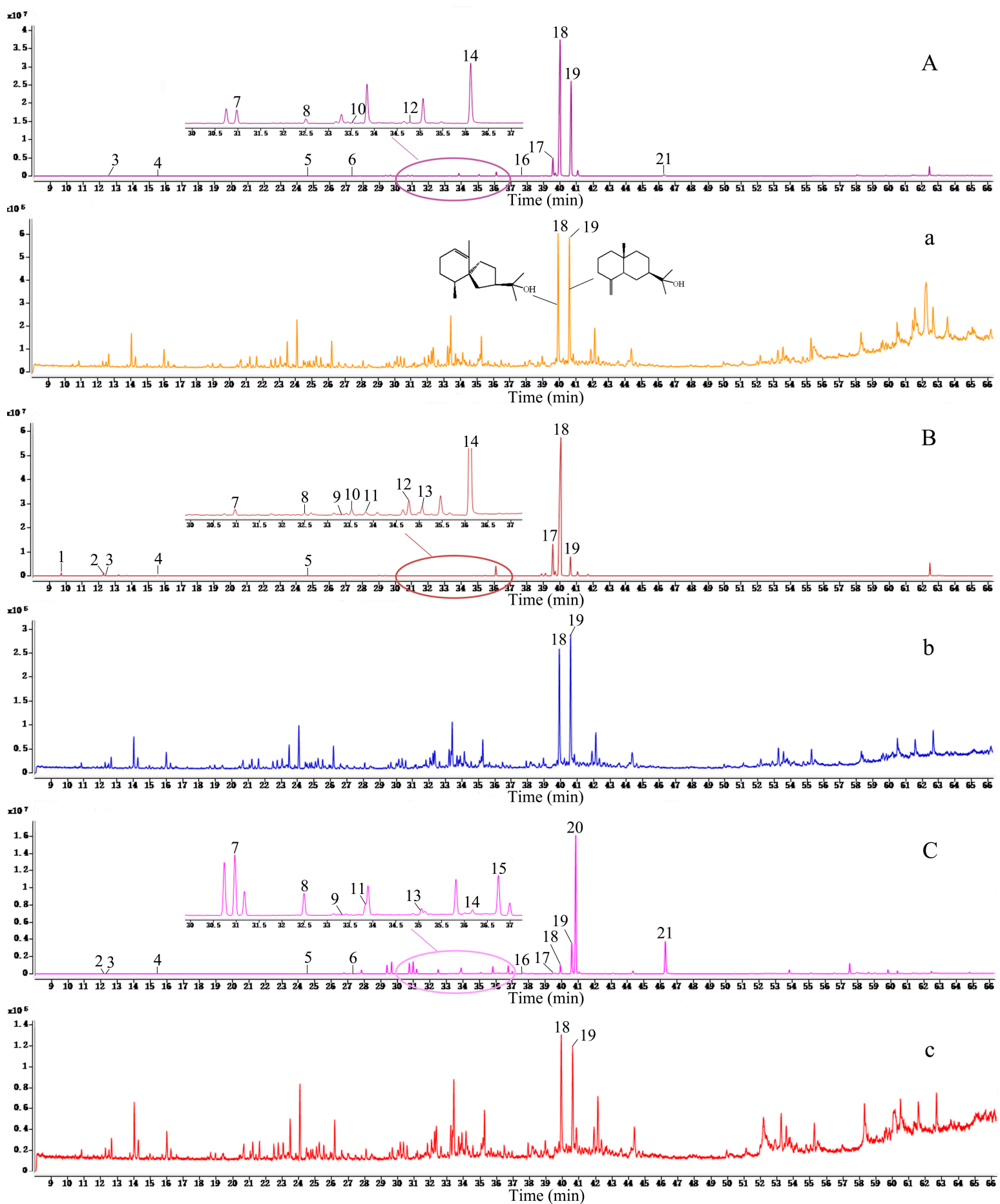

Figure 7. TIC chromatograms for Atractrylodes lancea from three regions: (A) A. lancea from Tongbai Mountain, Henan Province; (a) frosts of A. lancea from Tongbai Mountain, Henan Province; (B) A. lancea from Yuexi, Anhui Province; (b) frosts of A. lancea from Yuexi, Anhui Province; (C) A. lancea from Nanjing, Jiangsu Province; (c) frosts of A. lancea from Nanjing, Jiangsu Province. 
Table 1. Identification of compounds detected in Paeonia ostii and its frosts by UPLC-Q/TOF-MS $(n=3)$.

\begin{tabular}{|c|c|c|c|c|c|c|c|c|}
\hline \multirow{2}{*}{ Peak No. } & \multirow{2}{*}{$t_{R}(\min )$} & \multirow{2}{*}{$\begin{array}{l}\text { Molecular } \\
\text { Formula }\end{array}$} & \multirow{2}{*}{$\begin{array}{c}\text { Observed } \\
\text { Mass }(m / z)\end{array}$} & \multirow{2}{*}{$\begin{array}{l}\text { Mass Error } \\
\text { (ppm) }\end{array}$} & \multirow{2}{*}{ MS/MS(m/z) } & \multirow{2}{*}{ Identification } & \multicolumn{2}{|c|}{ Relative Content (\%) } \\
\hline & & & & & & & A & B \\
\hline 1 & 2.42 & $\mathrm{C}_{7} \mathrm{H}_{6} \mathrm{O}_{5}$ & 169.0150 & 7.7 & 125.0236 & Gallic acid & $0.14 \pm 0.03$ & - \\
\hline 2 & 2.54 & $\mathrm{C}_{18} \mathrm{H}_{24} \mathrm{O}_{14}$ & 463.1086 & -0.4 & $403.0870,373.0789,343.0667,301.0577$ & Mudanoside B & $0.03 \pm 0.01$ & - \\
\hline 3 & 4.42 & $\mathrm{C}_{23} \mathrm{H}_{28} \mathrm{O}_{12}$ & 495.1509 & 1.2 & $465.1407,137.0242$ & Oxypaeoniflorin & $3.16 \pm 0.45$ & - \\
\hline 4 & 4.95 & $\mathrm{C}_{15} \mathrm{H}_{14} \mathrm{O}_{6}$ & 289.0727 & 5.2 & $245.0827,137.0242$ & D-Catethin & $0.05 \pm 0.03$ & - \\
\hline 5 & 5.04 & $\mathrm{C}_{24} \mathrm{H}_{30} \mathrm{O}_{13}$ & 525.1609 & 0.2 & $495.1509,167.0336,165.0535$ & Mudanpioside E & $0.24 \pm 0.11$ & - \\
\hline 6 & 5.53 & $\mathrm{C}_{8} \mathrm{H}_{8} \mathrm{O}_{5}$ & 183.0285 & -4.4 & 124.0166 & Methyl gallate & $0.15 \pm 0.01$ & - \\
\hline 7 & 7.01 & $\mathrm{C}_{20} \mathrm{H}_{28} \mathrm{O}_{12}$ & 459.1496 & -1.5 & $293.0873,233.0674,165.0561$ & Paeonolide & $5.20 \pm 4.92$ & - \\
\hline 8 & 7.21 & $\mathrm{C}_{26} \mathrm{H}_{38} \mathrm{O}_{17}$ & 621.2020 & -1.8 & $455.1421,293.0418$ & Suffruticoside E & $0.38 \pm 0.48$ & - \\
\hline 9 & 8.40 & $\mathrm{C}_{23} \mathrm{H}_{28} \mathrm{O}_{11}$ & 479.1548 & -1.0 & $525.1609,449.1465,327.1075,165.0561,121.0292$ & Paeoniflorin & $9.14 \pm 1.05$ & - \\
\hline 10 & 9.58 & $\mathrm{C}_{27} \mathrm{H}_{32} \mathrm{O}_{16}$ & 611.1603 & -1.5 & $445.1009,283.0440,169.0150$ & Suffruticoside $\mathrm{A} / \mathrm{B} / \mathrm{C} / \mathrm{D}$ & $1.60 \pm 0.24$ & - \\
\hline 11 & 10.11 & $\mathrm{C}_{27} \mathrm{H}_{32} \mathrm{O}_{16}$ & 611.1653 & 6.7 & $445.1009,283.0475,169.0150,121.0292$ & Suffruticoside $\mathrm{A} / \mathrm{B} / \mathrm{C} / \mathrm{D}$ & $3.07 \pm 2.45$ & - \\
\hline 12 & 10.38 & $\mathrm{C}_{27} \mathrm{H}_{32} \mathrm{O}_{16}$ & 611.1603 & -1.5 & $445.1009,283.0440,165.1561$ & Suffruticoside $A / B / C / D$ & $1.15 \pm 0.21$ & - \\
\hline 13 & 11.36 & $\mathrm{C}_{27} \mathrm{H}_{32} \mathrm{O}_{16}$ & 611.1603 & -1.5 & $445.1009,283.0475,169.0150,121.0292$ & Suffruticoside $\mathrm{A} / \mathrm{B} / \mathrm{C} / \mathrm{D}$ & $2.78 \pm 0.63$ & - \\
\hline 14 & 12.64 & $\mathrm{C}_{30} \mathrm{H}_{32} \mathrm{O}_{14}$ & 615.1733 & -2.6 & $447.1279,431.1346,281.0681,137.0242$ & Mudanpioside $\mathrm{H}$ & $0.59 \pm 0.26$ & - \\
\hline 15 & 16.79 & $\mathrm{C}_{30} \mathrm{H}_{32} \mathrm{O}_{13}$ & 599.1752 & -2.2 & $477.1413,447.1279,431.1346,281.0681,137.0242$ & Mudanpioside C & $2.09 \pm 0.28$ & - \\
\hline 16 & 17.27 & $\mathrm{C}_{9} \mathrm{H}_{10} \mathrm{O}_{3}$ & 165.0561 & -2.2 & $150.0331,122.0353$ & Unidentified & $0.19 \pm 0.04$ & $8.73 \pm 3.44$ \\
\hline 17 & 18.14 & $\mathrm{C}_{30} \mathrm{H}_{32} \mathrm{O}_{13}$ & 599.1752 & 4.7 & $569.1677,477.1413,137.0228,165.0270,121.0270$ & Benzoyloxpaeoniflorin & $1.37 \pm 0.47$ & - \\
\hline 18 & 20.32 & $\mathrm{C}_{30} \mathrm{H}_{32} \mathrm{O}_{12}$ & 583.1804 & -2.1 & $629.1885,553.1722,431.1346,165.0561,121.0292$ & Benzoylpaeoniflorin & $4.89 \pm 2.41$ & - \\
\hline 19 & 22.20 & $\mathrm{C}_{9} \mathrm{H}_{10} \mathrm{O}_{3}$ & 165.0561 & 5.5 & $150.0331,122.0353$ & Paeonol & $0.65 \pm 0.49$ & $47.66 \pm 14.17$ \\
\hline
\end{tabular}

Note: under detection limit is denoted by (-); Suffruticoside A/B/C/D are isomers; for Relative Content, A: P. ostii; and B: frosts of P. ostii.

Table 2. Chemical characterization of Houpoëa officinalis and its frosts by UPLC-Q Orbitrap $(n=3)$.

\begin{tabular}{|c|c|c|c|c|c|c|c|c|}
\hline \multirow{2}{*}{ Peak no. } & \multirow{2}{*}{$t_{R}(\min )$} & \multirow{2}{*}{$\begin{array}{l}\text { Molecular } \\
\text { Formula }\end{array}$} & \multirow{2}{*}{$\begin{array}{l}\text { Observed } \\
\text { Mass }(m / z)\end{array}$} & \multirow{2}{*}{$\begin{array}{c}\text { Mass Error } \\
(\mathrm{ppm})\end{array}$} & \multirow{2}{*}{$\mathrm{MS}^{2} m / z$} & \multirow{2}{*}{ Proposed Compounds } & \multicolumn{2}{|c|}{ Relative Content (\%) } \\
\hline & & & & & & & A & B \\
\hline 1 & 9.64 & $\mathrm{C}_{19} \mathrm{H}_{22} \mathrm{O}_{5}$ & 329.1354 & -5.01 & $267.0998,249.0897,239.1043,221.0945,133.0631$ & Magnolignan D & $0.04 \pm 0.03$ & - \\
\hline 2 & 9.77 & $\mathrm{C}_{18} \mathrm{H}_{20} \mathrm{O}_{4}$ & 299.1255 & -7.64 & $239.1048,221.0945,133.0630$ & Magnolignan $\mathrm{A} / \mathrm{C}$ & $0.58 \pm 0.48$ & - \\
\hline 3 & 10.53 & $\mathrm{C}_{18} \mathrm{H}_{18} \mathrm{O}_{4}$ & 297.1099 & -7.52 & $253.0841,249.0904,239.1047,225.0890$ & Magnolignan E & $0.07 \pm 0.05$ & - \\
\hline 4 & 10.69 & $\mathrm{C}_{15} \mathrm{H}_{14} \mathrm{O}_{3}$ & 241.0841 & -7.55 & 223.0736, $197.0940,133.0642$ & Randaiol & $2.38 \pm 2.08$ & - \\
\hline 5 & 11.71 & $\mathrm{C}_{16} \mathrm{H}_{14} \mathrm{O}_{3}$ & 253.0841 & -7.19 & $235.0737,207.0790$ & Magnaldehyde D & $2.92 \pm 2.60$ & - \\
\hline 6 & 12.07 & $\mathrm{C}_{18} \mathrm{H}_{16} \mathrm{O}_{4}$ & 295.0944 & -7.07 & $251.1049,233.0942,231.0789$ & Dimethylstrobochrysin & $0.03 \pm 0.01$ & - \\
\hline 7 & 12.30 & $\mathrm{C}_{18} \mathrm{H}_{16} \mathrm{O}_{3}$ & 279.0996 & -7.06 & $261.0901,233.0948$ & Randainal & $0.35 \pm 0.15$ & - \\
\hline
\end{tabular}


Table 2. Cont.

\begin{tabular}{|c|c|c|c|c|c|c|c|c|}
\hline \multirow{2}{*}{ Peak no. } & \multirow{2}{*}{$t_{R}(\min )$} & \multirow{2}{*}{$\begin{array}{l}\text { Molecular } \\
\text { Formula }\end{array}$} & \multirow{2}{*}{$\begin{array}{l}\text { Observed } \\
\text { Mass }(m / z)\end{array}$} & \multirow{2}{*}{$\begin{array}{l}\text { Mass Error } \\
\quad(\mathrm{ppm})\end{array}$} & \multirow{2}{*}{$\operatorname{MS}^{2} m / z$} & \multirow{2}{*}{ Proposed Compounds } & \multicolumn{2}{|c|}{ Relative Content (\%) } \\
\hline & & & & & & & A & B \\
\hline 8 & 13.87 & $\mathrm{C}_{19} \mathrm{H}_{20} \mathrm{O}_{3}$ & 295.1302 & -9.05 & $295.1302,265.1206,263.1048,245.0945$ & 3-OMe-magnalol & $0.05 \pm 0.03$ & - \\
\hline 9 & 14.04 & $\mathrm{C}_{18} \mathrm{H}_{18} \mathrm{O}_{2}$ & 265.1205 & -6.81 & $224.0813,223.0740,197.0574$ & Honokiol & $15.95 \pm 6.28$ & $2.67 \pm 1.25$ \\
\hline 10 & 14.80 & $\mathrm{C}_{18} \mathrm{H}_{18} \mathrm{O}_{3}$ & 281.1151 & -7.54 & $164.0451,136.0377,133.0633$ & Obovatol & $2.90 \pm 1.67$ & - \\
\hline 11 & 14.94 & $\mathrm{C}_{18} \mathrm{H}_{18} \mathrm{O}_{2}$ & 265.1205 & -6.81 & 224.0813 & Magnolol & $44.43 \pm 3.59$ & $25.58 \pm 2.24$ \\
\hline
\end{tabular}

Note: under detection limit is denoted by (-); for Relative Content, A: H. officinalis; and B: frosts of H. officinalis.

Table 3. Chemical characterization of Atractylodes lancea and its frosts from three regions $(n=3)$.

\begin{tabular}{|c|c|c|c|c|c|c|c|c|c|c|}
\hline \multirow{2}{*}{ Peak No. } & \multirow{2}{*}{$t_{R}(\min )$} & \multirow{2}{*}{$\begin{array}{l}\text { Molecular } \\
\text { Formula }\end{array}$} & \multirow{2}{*}{$\begin{array}{c}\text { Molecular } \\
\text { Weight }\end{array}$} & \multirow{2}{*}{ Identification } & \multicolumn{6}{|c|}{ Relative Content (\%) } \\
\hline & & & & & A & $\mathbf{a}$ & B & $\mathbf{b}$ & $\mathrm{C}$ & c \\
\hline 1 & 9.73 & $\mathrm{C}_{10} \mathrm{H}_{16}$ & 136 & $\alpha$-Pinene & - & - & $0.41 \pm 0.23$ & - & - & - \\
\hline 2 & 12.28 & $\mathrm{C}_{10} \mathrm{H}_{16}$ & 136 & $\alpha$-phellandrene & - & - & $0.40 \pm 0.29$ & - & $0.11 \pm 0.09$ & - \\
\hline 3 & 12.41 & $\mathrm{C}_{10} \mathrm{H}_{16}$ & 136 & 3-Carene & $0.02 \pm 0.01$ & - & $0.14 \pm 0.08$ & - & $0.01 \pm 0.01$ & - \\
\hline 4 & 15.60 & $\mathrm{C}_{10} \mathrm{H}_{16}$ & 136 & Terpinolene & $0.02 \pm 0.01$ & - & $0.12 \pm 0.06$ & - & $0.01 \pm 0.01$ & - \\
\hline 5 & 24.73 & $\mathrm{C}_{12} \mathrm{H}_{20} \mathrm{O}_{2}$ & 196 & Bornyl acetate & $0.02 \pm 0.02$ & - & $0.04 \pm 0.01$ & - & $0.02 \pm 0.02$ & - \\
\hline 6 & 27.36 & $\mathrm{C}_{12} \mathrm{H}_{22} \mathrm{O}_{2}$ & 198 & Citronellyl acetate & $0.01 \pm 0.01$ & - & - & - & $0.05 \pm 0.02$ & - \\
\hline 7 & 30.97 & $\mathrm{C}_{15} \mathrm{H}_{24}$ & 204 & $\beta$-Caryophyllene & $0.22 \pm 0.16$ & - & $0.08 \pm 0.05$ & - & $2.66 \pm 0.53$ & - \\
\hline 8 & 32.50 & $\mathrm{C}_{15} \mathrm{H}_{24}$ & 204 & Humulene & $0.08 \pm 0.05$ & - & $0.03 \pm 0.02$ & - & $0.99 \pm 0.18$ & - \\
\hline 9 & 33.28 & $\mathrm{C}_{15} \mathrm{H}_{22}$ & 202 & $\alpha$-Curcumene & - & - & $0.01 \pm 0.00$ & - & $0.07 \pm 0.04$ & - \\
\hline 10 & 33.52 & $\mathrm{C}_{15} \mathrm{H}_{24}$ & 204 & $\beta$-Cubebene & $0.01 \pm 0.00$ & - & $0.05 \pm 0.01$ & - & - & - \\
\hline 11 & 33.83 & $\mathrm{C}_{15} \mathrm{H}_{24}$ & 204 & Zingiberene & - & - & $0.13 \pm 0.09$ & - & $1.60 \pm 0.26$ & - \\
\hline 12 & 34.78 & $\mathrm{C}_{15} \mathrm{H}_{24}$ & 204 & $\gamma$-Cadinene & $0.03 \pm 0.01$ & - & $0.13 \pm 0.03$ & - & - & - \\
\hline 13 & 35.07 & $\mathrm{C}_{15} \mathrm{H}_{24}$ & 204 & $\beta$-sesquiphellandrene & - & - & $0.09 \pm 0.02$ & - & $0.17 \pm 0.11$ & - \\
\hline 14 & 36.11 & $\mathrm{C}_{15} \mathrm{H}_{26} \mathrm{O}$ & 222 & Elemol & $1.19 \pm 0.47$ & - & $2.96 \pm 0.94$ & - & $0.18 \pm 0.04$ & - \\
\hline 15 & 36.75 & $\mathrm{C}_{15} \mathrm{H}_{24}$ & 204 & $\gamma$-elemene & - & - & - & - & $1.39 \pm 0.47$ & - \\
\hline 16 & 37.69 & $\mathrm{C}_{15} \mathrm{H}_{24} \mathrm{O}$ & 220 & Caryophyllene Oxide & $0.04 \pm 0.03$ & - & - & - & $0.30 \pm 0.12$ & - \\
\hline 17 & 39.56 & $\mathrm{C}_{15} \mathrm{H}_{26} \mathrm{O}$ & 222 & Agarospirol & $4.37 \pm 1.22$ & - & $7.80 \pm 2.11$ & - & $0.08 \pm 0.08$ & - \\
\hline 18 & 40.00 & $\mathrm{C}_{15} \mathrm{H}_{26} \mathrm{O}$ & 222 & Hinesol & $42.77 \pm 10.23$ & $5.10 \pm 3.13$ & $63.85 \pm 10.87$ & $7.56 \pm 2.45$ & $1.21 \pm 0.99$ & $3.61 \pm 1.94$ \\
\hline 19 & 40.66 & $\mathrm{C}_{15} \mathrm{H}_{26} \mathrm{O}$ & 222 & $\beta$ - Eudesmol & $40.81 \pm 11.75$ & $4.83 \pm 3.02$ & $12.45 \pm 13.18$ & $6.67 \pm 5.26$ & $5.47 \pm 3.37$ & $4.38 \pm 1.10$ \\
\hline 20 & 40.86 & $\mathrm{C}_{15} \mathrm{H}_{20} \mathrm{O}$ & 216 & Atractylon & - & - & - & - & $33.89 \pm 9.78$ & - \\
\hline 21 & 46.30 & $\mathrm{C}_{13} \mathrm{H}_{10} \mathrm{O}$ & 182 & Atractylodin & $0.36 \pm 0.23$ & - & & - & $13.53 \pm 5.07$ & - \\
\hline
\end{tabular}

Note: Under detection limit is denoted by (-); for Relative Content, A: A. lancea from Tongbai Mountain, Henan Province; a: frosts of $A$. lancea from Tongbai Mountain, Henan Province; B A. lancea from Yuexi, Anhui Province; b: frosts of A. lancea from Yuexi, Anhui Province; C: A. lancea from Nanjing, Jiangsu Province; c: frosts of $A$. lancea from Nanjing, Jiangsu Province. 
In this study, the ratio of the normalized relative percentage content of nine common peaks was selected as the basic parameter, and the average vector was selected as the control map. The similarity of the meteorological maps of the essential oil of $A$. lancea from three regions was calculated by the correlation coefficient method and the angle cosine method. The results showed that the similarity coefficients of the A. lancea from Henan, Yuexi, and Nanjing were 0.94, 0.96, and 0.41, respectively, and the angle cosines were $0.95,0.97$, and 0.57 , respectively. The main components of the A. lancea from Tongbai Mountain, Henan, and Yuexi, Anhui were hinesol (peak 18) and $\beta$-eudesmol (peak 19), which contained almost little or no atractylone (peak 20) and atractylodin (peak 21). The main compounds in A. lancea from Nanjing, Jiangsu were atractylone, atractylodin, and $\beta$-eudesmol, and smaller volumes of hinesol was found. However, the composition of the A. lancea frosts from three regions were same, and they were mainly composed of hinesol and $\beta$-eudesmol.

The main active constituents of $A$. lancea are essential oils, such as hinesol, $\beta$-eudesmol, atractylone, and atractylodin. However, according to its chemical constituents, $A$. lancea has different chemical types: the Dabieshan type and the Maoshan type [59]. Having hinesol and $\beta$-eudesmol in high concentrations, atractylodin at a low concentration, and atractylone with little to no presence is indicative of Dabieshan-type A. lancea. The Maoshan type of $A$. lancea has a high concentration of atractylone and atractylodin, and a low concentration of hinesol and $\beta$-eudesmol. This result is identical with its experimental results.

After slicing the A. lancea samples from these three regions, their sections have numerous cinnabar dots and white fine needle frosts, which precipitated out at the cross-section after a long waiting period. It was found that $A$. lancea frosts are more prominent in the Dabieshan type than in the Maoshan type. Previous reports suggested that the frosts of $A$. lancea were hinesol, $\beta$-eudesmol, and elemol [60], or hinesol and $\beta$-eudesmol [42]. With regard to the experimental materials of $A$. lancea in this experiment, although the chemical types of the A. lancea from the three areas were different, the frosts components were the same. They were mainly composed of hinesol and $\beta$-eudesmol, and lacked elemol, atractylone, and atractylodin. It can be inferred that hinesol and $\beta$-eudesmol are more likely to precipitate on the surface and form frosts.

\section{Materials and Methods}

\subsection{Sample Information}

The root bark of Paeonia ostii T. Hong et J. X. Zhang was collected from Tongling city in Anhui Province; the root bark of Houpoëa officinalis (Rehder and E. H. Wilson) N. H. Xia and C. Y. Wu. was purchased from Gaosheng Street, Hong Kong. The healthy plants of Atractylodes lancea (Thunb.) DC. were collected from Henan Province, Anhui Province and Jiangsu Province, respectively. Sample information is provided in Table S1. All samples were authenticated by Professor Huasheng Peng (School of Pharmacy, Anhui University of Chinese Medicine)

\subsection{Chemicals and Reagents}

Magnolol, honokiol, and $\alpha$-Pinene were purchased from Chengdu DeSiTe Biological Technology Co., Ltd. (Chengdu, Sichuan, China). The $\beta$-eudesmol and atractylon were purchased from Shanghai yuanye Bio-Technology Co., Ltd. (Shanghai, China). The atractylodin was purchased from Alfa Biotechnology (Chengdu, Sichuan, China). The paeonol was purchased from Shanghai YS Industrial CO., Ltd. (Shanghai, China). Methanol and acetonitrile (HPLC-grade) were purchased from TEDIA (Cincinnati, OH, USA). Formic acid of over 98\% purity was purchased from Aladdin (Los Angeles, CA, USA). N-hexane was purchased from Tianjin Guangfu Science and Technology Development Co., Ltd. (Tianjin, China). All chemicals were of chromatographic grade. Water was prepared by a Direct-Pure Water System (Shanghai, China). 


\subsection{Microscopic Analysis}

The root bark of P. ostii was dried in the shade until frosts precipitated on the surface. The fresh rhizomes of $A$. lancea were cut vertically and put at $4{ }^{\circ} \mathrm{C}$ for precipitating frost. The frosts were observed by metalloscope and collected by tweezers. The frosts were observed in normal and polarized light under a microscope (Leica DM6000B), utilizing LAS (Leica Applications Suite V4.1) software by the method of temporary section.

\subsection{Macroscopic Raman Spectroscopy}

Raman spectra were recorded using a LabRAM HR Evolution, which has $785 \mathrm{~nm}$ and $532 \mathrm{~nm}$ laser sources. The frosts of $P$. ostii and paeonol were placed on a glass slide, with the frosts of $H$. officinalis, magnolol, and honokiol on another glass slide, and the surface was flattened so that the authors could place the slide under the objective view of the laser micro-Raman spectrometer platform. The focal length was adjusted through the influence window on the screen of the microcomputer. Spectra of frosts of P. ostii and paeonol were obtained in the range of $100-2000 \mathrm{~cm}^{-1}$ at a resolution of $1 \mathrm{~cm}^{-1}$. Spectra of frosts of H. officinalis, magnolol, and honokiol were obtained in the range of $100-3000 \mathrm{~cm}^{-1}$ at a resolution of $1 \mathrm{~cm}^{-1}$.

\subsection{UPLC-Q/TOF-MS Analysis of P. ostii}

\subsubsection{Sample Preparation}

The root bark of $P$. ostii was shade-dried to a constant weight and ground into power though a 60-mesh sieve. The dry power (approximately $0.15 \mathrm{~g}$ ) was mixed with $25 \mathrm{~mL}$ of $70 \%$ methanol and weighed, and then the ultrasonic treatment was applied with JK-5200B (Hefei Jinnick Machinory Manufacturing Co. Ltd.) at room temperature, $40 \mathrm{KHz}$, and $200 \mathrm{~W}$ for $30 \mathrm{~min}$, using a bath with $300 \times 240 \times 150 \mathrm{~mm}$ in diameter. Then $70 \%$ methanol was added to the mixture to compensate for the loss of weight. The mixture was subsequently filtered through a $0.22 \mu \mathrm{m}$ microporous filter membrane and stored at $4{ }^{\circ} \mathrm{C}$ until use for UPLC-Q/TOF-MS analysis.

The frosts of $P$. ostii (approximately $1.01 \mathrm{mg}$ ) were mixed with $1 \mathrm{~mL}$ of $70 \%$ methanol, subjected at room temperature, $40 \mathrm{KHz}$, and $200 \mathrm{~W}$ to ultrasonic treatment for $30 \mathrm{~min}$, using a bath $300 \times 240$ $\times 150 \mathrm{~mm}$ in diameter. The mixture was subsequently filtered through a $0.22 \mu \mathrm{m}$ microporous filter membrane and stored at $4{ }^{\circ} \mathrm{C}$ until use for UPLC-Q/TOF-MS analysis.

An appropriate amount of paeonol standard was dissolved in $70 \%$ methanol, and the concentrations of standard solutions was $1.12 \mathrm{mg} / \mathrm{mL}$. The mixture was subsequently filtered through a $0.22 \mu \mathrm{m}$ microporous filter membrane and stored at $4{ }^{\circ} \mathrm{C}$ until use for UPLC-Q/TOF-MS analysis.

\subsubsection{UPLC-Q/TOF-MS Method}

Chemical profile analysis of the root bark of P. ostii and frosts was performed on a Waters Xevo G2-XS quadruple time-of-flight spectrometer (Waters, Milford, MA, USA), which was coupled with UNIFI v1.7.1 software (WatersCorp, Milford, MA, USA). Chromatographic separation was performed on an Acquity UPLC BEH C18 Column $(2.1 \mathrm{~mm} \times 100 \mathrm{~mm}, 1.7 \mu \mathrm{m}$; Waters $)$ and a C18 Pre-column $(2.1 \mathrm{~mm} \times 100 \mathrm{~mm}, 1.7 \mu \mathrm{m}$; Waters). The mobile phase consisting of acetonitrile and $0.1 \%$ formic acid aqueous solution was used. The following gradient elution program was used for separation: 0-15 $\mathrm{min}, 10 \%-25 \%$ acetonitrile; $15-18 \mathrm{~min}, 25 \%-35 \%$ acetonitrile; $18-19 \mathrm{~min}, 35 \%-55 \%$ acetonitrile; 19-22 $\mathrm{min}, 35 \%-55 \%$ acetonitrile; $22-25 \mathrm{~min}$, and $55 \%-85 \%$ acetonitrile. The flow rate was $0.2 \mathrm{~mL} / \mathrm{min}$, the injection volume was $2 \mathrm{uL}$, and the column temperature was maintained at $30^{\circ} \mathrm{C}$.

In the negative ionization mode, mass spectra were recorded over the range of 50-1200 m/z under the following conditions: the capillary source, sampling cone source, source offset, and source temperature were $2.0 \mathrm{kV}, 40,80$, and $120^{\circ} \mathrm{C}$, respectively. The cone gas flow rate was $50 \mathrm{~L} / \mathrm{h}$, and the desolation gas flow rate was $600 \mathrm{~L} / \mathrm{h}$. Leucine enkephalin was used to calibrate the mass spectrometer. Calculating the relative percentage content of each compound was done by peak area normalization. 


\subsection{UPLC-Q Orbitrap Analysis}

\subsubsection{Sample Preparation}

The root bark of $H$. officinalis was dried to a constant weight at $40{ }^{\circ} \mathrm{C}$ and ground into powder though a 60 -mesh sieve. The dry powder (approximately $0.05 \mathrm{~g}$ ) was mixed with $20 \mathrm{~mL}$ methanol, weighed, and subjected to ultrasonic treatment at room temperature, $40 \mathrm{KHz}$, and $200 \mathrm{~W}$ for $30 \mathrm{~min}$, using a bath $300 \times 240 \times 150 \mathrm{~mm}$ in diameter. Methanol was added to the mixture to compensate for the loss of weight. The mixture was subsequently filtered through a $0.22 \mu \mathrm{m}$ microporous filter membrane and stored at $4{ }^{\circ} \mathrm{C}$ until use for analysis.

Appropriate amounts of the frosts of $H$. officinalis were dissolved in methanol, subjected to ultrasonic treatment at room temperature, $40 \mathrm{KHz}$ and $200 \mathrm{~W}$ for $30 \mathrm{~min}$, using a bath $300 \times 240 \times$ $150 \mathrm{~mm}$ in diameter. The mixture was subsequently filtered through a $0.22 \mu \mathrm{m}$ microporous filter membrane and stored at $4{ }^{\circ} \mathrm{C}$ until use for analysis.

Appropriate amount of magnolol and honokiol were dissolved in methanol, and the concentrations of the standard solutions were $50.5 \mu \mathrm{g} / \mathrm{mL}$ and $54.0 \mu \mathrm{g} / \mathrm{mL}$, respectively. The mixture was subsequently filtered through a $0.22 \mu \mathrm{m}$ microporous filter membrane and stored at $4{ }^{\circ} \mathrm{C}$ until use for analysis.

\subsubsection{UPLC-Q Orbitrap Method}

Chromatographic separation was performed using a Q Extractive Plus (Thermo Fisher Scientific, United States). An Acquity UPLC BEH C18 Column $(2.1 \mathrm{~mm} \times 100 \mathrm{~mm}, 1.7 \mu \mathrm{m})$ with a C18 Pre-column $(2.1 \mathrm{~mm} \times 100 \mathrm{~mm}, 1.7 \mu \mathrm{m})$ was used. The mobile phase consisting of acetonitrile and $0.1 \%$ formic acid aqueous solution was used. The following gradient elution program was used for separation: 0-13 min, $5 \%-75 \%$ acetonitrile; $13-17 \mathrm{~min}, 75 \%-90 \%$ acetonitrile; $17-19 \mathrm{~min}, 90 \%-100 \%$ acetonitrile. The flow rate was $0.2 \mathrm{~mL} / \mathrm{min}$, the injection volume was $2 \mathrm{uL}$, and the column temperature was maintained at $30^{\circ} \mathrm{C}$.

Mass spectrometry (MS) analysis was performed on a Q Extractive Plus Orbitrap mass spectrometer (Thermo Fisher Scientific, Waltham, MA, USA), which was equipped with an electron spray ionization opening in negative ionization mode. The MS parameters were set as follows: spray voltage at $4.5 \mathrm{kV}$, ionization temperature at $550^{\circ} \mathrm{C}$, and collision energy at $10 \mathrm{eV}$. The scanning range of primary mass spectrometry was 100-2000, and that of secondary mass spectrometry was 50-1000. Instrument control and data processing were carried out by Xcalibur software 2.2.0 (Thermo Fisher Scientific, USA). Calculating the relative percentage content of each compound was by peak area normalization.

\subsection{Gas Chromatography-Mass Spectrometry Analysis}

\subsubsection{Sample Preparation}

The A. lancea rhizome was dried to a constant weight at $50^{\circ} \mathrm{C}$, and ground into powder though a 50-mesh sieve. The dry power $(0.2 \mathrm{~g})$ was mixed with $6 \mathrm{~mL} \mathrm{~N}$-hexane, weighed, and subjected to ultrasonic treatment at room temperature, $40 \mathrm{KHz}$, and $200 \mathrm{~W}$ for $30 \mathrm{~min}$, using a bath $300 \times 240$ $\times 150 \mathrm{~mm}$ in diameter. N-hexane was added to the mixture to compensate for the loss of weight. The mixture was subsequently filtered through a $0.22 \mu \mathrm{m}$ microporous filter membrane and stored at $4{ }^{\circ} \mathrm{C}$ until use for GC-MS analysis.

An appropriate amount of frost in A. lancea was dissolved in N-hexane and subjected to ultrasonic treatment at room temperature, $40 \mathrm{KHz}$, and $200 \mathrm{~W}$ for $30 \mathrm{~min}$, using a bath $300 \times 240 \times 150 \mathrm{~mm}$ in diameter. The mixture was subsequently filtered through a $0.22 \mu \mathrm{m}$ microporous filter membrane and stored at $4{ }^{\circ} \mathrm{C}$ until use for analysis.

Reference standards were dissolved in N-hexane, and the concentrations of standard solutions were as follows: $\alpha$-Pinene $=17.16 \mu \mathrm{g} / \mathrm{mL}$; atractylone $=100.0 \mu \mathrm{g} / \mathrm{mL}, \beta$-eudesmol $=90.0 \mu \mathrm{g} / \mathrm{mL}$; and atractylodin $=100.0 \mu \mathrm{g} / \mathrm{mL}$. 


\subsubsection{Gas Chromatography-Mass Spectrometry Analysis and Metabolite Identification}

An Agilent 7890B gas chromatograph system, equipped with a flame ionization detector (FID) and DB-5 column $(30 \mathrm{~m} \times 0.25 \mathrm{~mm} ; 25 \mu \mathrm{m})$, was used for analysis. High purity helium $(>99.999 \%)$ was used as the carrier gas. Chromatographic conditions and mass spectrometric conditions are as referred to by Ouyang [37]. The initial GC oven temperature was kept at $85^{\circ} \mathrm{C}$ for $5 \mathrm{~min}$, then increased up to $185^{\circ} \mathrm{C}$ by $3^{\circ} \mathrm{C} / \mathrm{min}$, held constant at $185^{\circ} \mathrm{C}$ for $10 \mathrm{~min}$, then increased to $250{ }^{\circ} \mathrm{C}$ by $5^{\circ} \mathrm{C} / \mathrm{min}$ and held for $5 \mathrm{~min}$. The split ratio was 1:40, and the injection volume was $2 \mu \mathrm{L}$.

The interface temperature and ion source temperature were $280^{\circ} \mathrm{C}$ and $230^{\circ} \mathrm{C}$, respectively. Mass spectra were recorded from 33 to $350 \mathrm{~m} / \mathrm{z}$ in full scan mode with an electron ionization source at $70 \mathrm{eV}$, and the solvent delay time was $5 \mathrm{~min}$. The NIST11 database was used for the identification of substances. Calculating the relative percentage content of each compound was done by peak area normalization.

\section{Conclusions}

Through the analysis of frosts in P. ostii, H. officinalis, and A. lancea, it was found that the secondary metabolites of the three medicinal plants accumulated and precipitated in the plants' medicinal parts. Therefore, this experiment proves, to a certain degree, that the traditional identification, through experience, of ancient Chinese medicinal plants based on frost precipitation is scientifically corroborated. The secondary metabolites of these three medicinal plants are mainly composed of two or more components, such as P. ostii, H. officinalis, and A. lancea. For different chemical types of A. lancea, although the proportion of active components are different, the main components of the frosts in A. lancea are same: they are both hinesol and $\beta$-eudesmol.

Supplementary Materials: The following are available online at http://www.mdpi.com/1420-3049/24/24/4548/s1, Table S1: Sample information.

Author Contributions: Conceptualization, D.Q.Y., L.P.Z., and H.S.P.; data curation, D.Q.Y., X.J.H., and T.Y.S.; funding acquisition, L.P.Z. and H.S.P.; investigation, L.P.Z.; methodology, D.Q.Y., T.Y.S., and R.X.; project administration, L.P.Z. and H.S.P.; resources, D.Q.Y., L.P.Z., and H.S.P.; software, D.Q.Y. and T.Y.S.; validation, R.X., J.H., and W.X.C.; writing —original draft, D.Q.Y.; writing—review and editing, D.Q.Y. and X.J.H.

Funding: This research was supported by the National Natural Science Foundation of China (81703633, 81573543, 81803675); the Anhui Provincial Natural Science Foundation (1808085QH290), the Special Fund for Guiding Local Science and Technology Development, awarded by the Central Government of Anhui Province (YDZX20183400004233); and the key project at the central government level: the Ability Establishment of Sustainable Use for Valuable Chinese Medicine Resources (2060302).

Acknowledgments: The authors thank the Center for Scientific Research of Anhui Medical University for valuable help in our experiment.

Conflicts of Interest: The authors declare no conflict of interest.

\section{References}

1. Hu, Z.H. Anatomy of Plant Secretory Structure; Shanghai Scientific \& Technical Publishers: Shanghai, China, 2012.

2. Taban, A.; Saharkhiz, M.J.; Niakousari, M. Sweet bay (Laurus nobilis L.) essential oil and its chemical composition, antioxidant activity and leaf micromorphology under different extraction methods. Sustain. Chem. Pharm. 2018, 9, 12-18. [CrossRef]

3. Francoz, E.; Ranocha, P.; Burlat, V.; Dunand, C. Arabidopsis seed mucilage secretory cells: regulation and dynamics. Trends Plant Sci. 2015, 20, 515-524. [CrossRef] [PubMed]

4. Chu, Q.G.; Hu, Z.H. Comparative anatomy of oil cells and mucilage cells in the leaves of the Lauraceae in China. Acta Phytotaxon. Sin. 1999, 37, 529-540.

5. Hu, Z.H. Studies on the structure and the ontogeny of the laticiferous canals of Decaisnea fargesii Franch. Acta Bot. Sin. 1963, 11, 129-135.

6. Renner, T.; Specht, C.D. Inside the trap: Gland morphologies, digestive enzymes, and the evolution of plant carnivory in the Caryophyllales. Curr. Opin. Plant Biol. 2013, 16, 436-442. [CrossRef] 
7. Liu, C.C.; Srividya, N.; Parrish, A.N.; Yue, W.; Shan, M.Q.; Wu, Q.A.; Lange, B.M. Morphology of glandular trichomes of Japanese catnip (Schizonepeta tenuifolia Briquet) and developmental dynamics of their secretory activity. Phytochemistry 2018, 150, 23-30. [CrossRef]

8. Olsson, M.E.; Olofsson, L.M.; Lindahl, A.; Lundgren, A.; Brodelius, M.; Brodelius, P.E. Localization of enzymes of artemisinin biosynthesis to the apical cells of glandular secretory trichomes of Artemisia annua L. Phytochemistry 2009, 70, 1123-1128. [CrossRef]

9. Cristina, R.; Caroline, M.M.; Taisa, C.O.; Fernanda, M.S.; Lilian, A.O.; Gaspar, H.K.; Regina, M.Q.L.; Monica, L.R.; Neusa, L.N.; Xavier, S.; et al. Si-accumulation in Artemisia annua glandular trichomes increases artemisinin concentration, but does not interfere in the impairment of Toxoplasma gondii growth. Front. Plant Sci. 2016, 7, 1-14.

10. Sanadhya, P.; Agarwal, P.; Agarwal, P.L. Ion homeostasis in a salt-secreting halophytic grass. AoB Plants 2015, 7, plv055. [CrossRef]

11. Wightman, R.; Wallis, S.; Aston, P. Hydathode pit development in the alpine plant Saxifraga cochlearis. Flora 2017, 233, 99-108. [CrossRef]

12. Wightman, R.; Wallis, S.; Aston, P. Leaf margin organization and the existence of vaterite-producing hydathodes in the alpine plant Saxifraga scardica. Flora 2018, 241, 27-34. [CrossRef]

13. Zhou, C.H.; Sheng, Y.L.; Zhao, D.Q.; Wang, Z.Q.; Tao, J. Variation of oleanolic and ursolic acid in the flesh of persimmon fruit among different cultivars. Molecules 2010, 15, 6580-6587. [CrossRef] [PubMed]

14. Li, S.Z. Compendium of Meteria Medica; People's Medical Publishing House: Beijing, China, 1982; Volume II.

15. Jin, S.Y. Traditional identification experience of traditional Chinese medicine in Jin Shiyuan, 2nd ed.; China Press of Traditional Chinese Medicine: Beijing, China, 2012.

16. Lin, L.; Jin, L.; Gao, S.F.; Chen, H.G.; Shi, X.L. Studies on the internal relationship between traditional identification term in Chinese medicine and pharmaceutical botany. China Pharm. 2015, 26, 3870-3874.

17. Zhao, Z.Z.; Liang, Z.T.; Guo, P. Macroscopic identification of Chinese medicinal materials: Traditional experiences and modern understanding. J. Ethnopharmacol. 2011, 134, 556-564. [CrossRef] [PubMed]

18. Collective Edition of Teaching and Research Group of Pharmacology, Nanjing Pharmaceutical College. Pharmacology; People's Medical Publishing House: Beijing, China, 1960.

19. Shanghai Branch of Chinese Pharmaceutical Association, Shanghai Pharmaceutical Company. Compilation of Medicinal Materials; Shanghai Scientific \& Technical Publishers: Shanghai, China, 1959; Volume I.

20. Lou, Z.Q.; Qin, B. Species Systematization and Quality Evaluation of Commonly Used Chinese Traditional Drugs, North-China ed.; Peking University Medical Press: Beijing, China, 1995; Volume III.

21. Shang, Z.J. The Collation and Annotation of Sheng Nong's Herbal Classic; Academy Press: Beijing, China, 2008.

22. Hong, D.Y.; Pan, K.Y. Taxonomical history and revision of Paeonia sect. Moutan (Paeoniaceae). Acta Phytotaxon. Sin. 1999, 37, 351-368.

23. Han, C.J.; Wang, Q.; Zhang, H.B.; Wang, S.H.; Song, H.D.; Hao, J.M.; Dong, H.Z. Light shading improves the yield and quality of seed in oil-seed peony (Paeonia ostii Feng Dan). J. Integr. Agr. 2018, 17, 1631-1640. [CrossRef]

24. Wei, X.B.; Xue, J.Q.; Wang, S.L.; Xue, Y.Q.; Lin, H.; Shao, X.F.; Xu, D.H.; Zhang, X.X. Fatty acid analysis in the seeds of 50 Paeonia ostii individuals from the same population. J. Integr. Agr. 2018, 17, 1758-1767. [CrossRef]

25. Tian, X.; Guo, S.; Zhang, S.S.; Li, P.S.; Wang, T.Y.; Ho, C.T.; Pan, M.H.; Bai, N.S. Chemical characterization of main bioactive constituents in Paeonia ostii seed meal and GC-MS analysis of seed oil. J. Food Biochem. 2019, e13088. [CrossRef]

26. Liu, P.; Zhang, L.N.; Wang, X.S.; Gao, J.Y.; Yi, J.P.; Deng, R.X. Characterization of Paeonia ostii seed and oil sourced from different cultivation areas in China. Ind. Crops Prod. 2019, 133, 63-71. [CrossRef]

27. Wang, G.C.; Liu, Z.J. Cultivation, Appreciation and Cultural Origin Culture of Chinese Peony; Forestry Press: Beijing, China, 2001.

28. Zhang, L.; Li, D.C.; Liu, L.F. Peaonol: Pharmacological effects and mechanisms of action. Int. Immunopharmacol. 2019, 72, 413-421. [CrossRef]

29. Khalid, S.; Khan, A.; Shal, B.; Ali, H.; Kim, Y.S.; Khan, S. Suppression of TRPV1 and P2Y nociceptors by honokiol isolated from Magnolia officinalis in 3rd degree burn mice by inhibiting inflammatory mediators. Biomed. Pharmacother. 2019, 114, 108777. [CrossRef] [PubMed] 
30. Hu, Y.; Shen, Y.F.; Tu, X.; Wu, X.H.; Wang, G.X.; Ling, F. Isolation of anti-Saprolegnia lignans from Magnolia officinalis and SAR evaluation of honokiol/magnolol analogs. Bioorg. Med. Chem. Lett. 2019, 29, 389-395. [CrossRef] [PubMed]

31. Chen, Y.H.; Lu, M.H.; Guo, D.S.; Zhai, Y.Y.; Miao, D.; Yue, J.Y.; Yuan, C.H.; Zhao, M.M.; An, D.R. Antifungal effect of magnolol and honokiol from Magnolia officinalis on Alternaria alternate causing tobacco brown spot. Molecules 2019, 24, 2140. [CrossRef] [PubMed]

32. Hu, H.L.; Wang, Z.G.; Hua, W.; You, Y.; Zou, L. Effect of chemical profiling change of processed Magnolia officinalis on the pharmacokinetic profiling of honokiol and magnolol in rats. J. Chromatogr. Sci. 2016, 54, 1201-1212. [CrossRef]

33. Jun, X.; Fu, P.; Lei, Y.; Cheng, P. Pharmacological effects of medicinal components of Atractylodes lancea (Thunb.) DC. Chin. Med. 2018, 13, 59. [CrossRef]

34. Guo, W.Q.; Liu, S.B.; Ju, X.; Du, J.H.; Xu, B.; Yuan, H.X.; Qin, F.J.; Li, L.Z. The antitumor effect of hinesol, extract from Atractylodes lancea (Thunb.) DC. by proliferation, inhibition, and apoptosis induction via MEK/ERK and NF- $\chi$ B pathway in non-small cell lung cancer cell lines A549 and NCI-H1299. J. Cell. Biochem. 2019, 120, 18600-18607. [CrossRef]

35. Kesara, N.B.; Tullayakorn, P.; Juntra, K. Research and development of Atractylodes lancea (Thunb) DC. as a promising candidate for cholangiocarcinoma chemotherapeutics. Evid-Based Compl. Alt. 2017, 2017, 1-16.

36. Chen, Q.H.; Li, P.; Yang, H.D.; Li, X.L.; Zhu, J.; Chen, F.C. Identification of volatile compounds of Atractylode lancea Rhizoma using supercritical fluid extraction and GC-MS. J. Sep. Sci. 2009, 32, 3152-3156. [CrossRef]

37. Ouyang, Z.; Zhang, L.; Zhao, M.; Wang, P.X.; Wei, Y.; Fang, J. Identification and quantification of sesquiterpenes and polyacetylenes in Atractylodes lancea from various geographical origins using GC-MS analysis. Rev. Bras. Farmacogn. 2012, 22, 1-7. [CrossRef]

38. Zhan, Z.L.; Deng, A.; Kang, L.P.; Tang, J.F.; Nan, T.F.; Chen, T.; He, Y.L.; Guo, L.P.; Huang, L.Q. Chemical profiling in Moutan Cortex after sulfuring and desulfuring processes reveals further insights into the quality control of TCMs by nontargeted metabolomic analysis. J. Pharm. Biomed. Anal. 2018, 156, 340-348. [CrossRef]

39. Wang, Y.Q.; Hu, L.P.; Liu, G.M.; Zhang, D.S.; He, H.J. Evaluation of the nutritional quality of Chinese kale (Brassica alboglabra Bailey) using UHPLC-Quadrupole-Orbitrap MS/MS-based metabolomics. Molecules 2017, 22, 1262. [CrossRef] [PubMed]

40. Wang, Y.G.; Li, X.R.; Jiang, Q.J.; Sun, H.N.; Jiang, J.F.; Chen, S.M.; Guan, Z.Y.; Fang, W.M.; Chen, F.D. GC-MS analysis of the volatile constituents in the leaves of 14 Compositae plants. Molecules 2018, 23, 166. [CrossRef] [PubMed]

41. Chinese Pharmacopoeia Commission, Institute of Medicinal Plant Development Chinese Academy of Medical Sciences. A Colored Identification Atlas of Chinese Materia Medica and Plant as Specified in the Pharmacopoeia of the People's Republic of China; People's Medical Publishing House: Beijing, China, 2010.

42. Zhao, Z.Z.; Chen, H.B. Illustrated Chinese Materia Medica, 2nd ed.; Fujian Science \& Technology Publishing House: Fuzhou, China, 2018.

43. Cai, P.Y. Raman Study on Drug Molecules and Organic Molecules; Southwest University: Chongqing, China, 2011.

44. Zhu, Z.Y.; Gu, R.N.; Lu, T.H. Application of Raman Spectroscopy in Chemistry; Northeast University Press: Shenyang, China, 1998.

45. Li, S.S.; Wu, Q.; Yin, D.D.; Peng, C.Y.; Liu, Z.A.; Wang, L.S. Phytochemical variation among the traditional Chinese medicine Mu Dan Pi from Paeonia suffruticosa (tree peony). Phytochemistry 2018, 146, 16-24. [CrossRef] [PubMed]

46. Hu, Y.F.; Pei, Y.M.; Wu, H.; Xu, Q.; Xu, G.B.; Jiang, L.; Zhou, J.L. Difference analysis of chemical compositions in moutan cortex from different origins by UPLC-Q/TOF-MS. Chin. Tradit. Herb. Drugs 2016, 47, 2984-2992.

47. Han, C.M.; Zhu, J.B.; Ding, Y.; Kou, Z.N.; Wang, Z.Z.; Xiao, W. Analysis of chemical components in methanol extract of Moutan Cortex by UPLC/Q-TOF-MS. J. Dalian Polytech. Univ. 2014, 33, 166-170.

48. Xiao, C.N.; Wu, M.; Chen, Y.Y.; Zhang, Y.J.; Zhao, X.F.; Zheng, X.H. Revealing metabolomic variations in Cortex Moutan from different root parts using HPLC-MS method. Phytochem. Analysis. 2015, 26, 86-93. [CrossRef]

49. Li, J.H.; Zeng, R.; Qu, Y.; Huang, L.F. Rapid identification on chemical constituents in roots of Paeonia delavayi var. lutea by UPLC-Q-TOF-MS ${ }^{\mathrm{E}}$ combined with UNIFI informatics platform. Chin. Tradit. Herb. Drugs 2017, $48,1529-1536$. 
50. Zhou, G.; Lv, Q.H. Studies on content determination and fingerprint of active constituents in different parts of Cortex Moutan. J. Chin. Mater. Med. 2008, 33, 2070-2073.

51. Guo, J.Y.; Li, S.B.; Hou, Y.Z.; Shi, M.K.; Pei, Y.F.; Zhang, J.Y.; Ji, R.L. Study on polyphenol contents in different parts of peony. Food Sci. Technol. 2008, 29, 348-350.

52. Fan, X.H.; Ma, T.C.; Shen, X.; Zhang, W.T.; Bi, K.S.; Jia, Y. UPLC determination of six active components in different parts of Moutan Cortex from different habitats. Chin. Tradit. Pat. Med. 2012, 34, 317-320.

53. Wang, L. The Study on Modern Processing Method and UPLC-DAD-TOF-MS Fingerprint of Wen-Hou-Po; Henan University of Chinese Medicine: Zhengzhou, China, 2010.

54. Zhao, H.; Yan, Y.; Zou, L.S.; Liu, X.H.; Chai, C.; Hua, Y.J.; Wang, S.N. Identification of chemical constituents in Magnoliae officinalis cortex by UFLC-Triple TOF-MS/MS. Chin Pharm. J. 2017, 52, 1824-1831.

55. Zhao, H.; Yan, Y.; Zou, L.S.; Liu, X.H.; Chai, C.; Hui, Y.J.; Wang, S.N. Difference of chemical compositions in "Chuanpu" and "Wenpu" based on LC-MS/MS and GC-MS/MS. Nat. Prod. Res. Dev. 2018, 30, 1-9.

56. Ji, L.; Ao, P.; Pan, J.G.; Yang, J.Y.; Yang, J.; Hu, S.L. GC-MS analysis of essential oils from rhizomes of Atractylodes lancea (Thunb.) DC. and A. chinensis (DC.) Koidz. China J. Chin. Mater. Med. 2001, 26, 182-185.

57. Gao, Y.; Wang, Z.B.; Yang, C.J.; Wu, G.S.; Chen, Y.J.; Kuang, H.X. Analysis on the volatile components of Atractylodes lancea from different origins by GC-MS. Acta Chin. Med. Pharmacol. 2017, 45, 35-38.

58. Zhou, J.Y.; Li, X.; Zheng, J.Y.; Dai, C.C. Volatiles released by endophytic Pesudomonas flurorescens promoting the growth and volatile oil accumulation in Atractylodes lancea. Plant Physiol. Bioch. 2016, 101, 132-140. [CrossRef]

59. Wang, F.; Ouyang, Z.; Guo, L.P.; Zhao, M.; Peng, H.S.; Liao, J.L.; Liang, Z.P. Comprehensive chemical pattern recognition of Atractylodis Rhizomes. China J. Chin. Mater. Med. 2014, 39, 2536-2541.

60. Yoichi, N.; Yohya, W.; Takako, S. Studies on the evaluation of crude drugs (I) comparative studies on the components of Atractylodes Rhizomes. Syôyakugaku Zasshi 1975, 29, 139-146.

Sample Availability: Samples of the compounds are available from the authors.

(C) 2019 by the authors. Licensee MDPI, Basel, Switzerland. This article is an open access article distributed under the terms and conditions of the Creative Commons Attribution (CC BY) license (http://creativecommons.org/licenses/by/4.0/). 